\title{
Adaptation and Resilience of Interdependent Infrastructure Systems: a Complex Systems Perspective
}

\author{
Liz Varga', Jim Harris ${ }^{2}$ \\ ${ }^{1}$ Complex Systems Research Centre, Cranfield University, UK. \\ 2 School of Energy, Environment and Agrifood, Cranfield University, UK.
}

\begin{abstract}
The effects of disruption upon one or more components in interdependent infrastructure systems and the ability of the system to return to normal operations, is investigated in this paper. This addresses the concept of resilience, and examines the trade-off between redundancy and efficiency, as well as the adaptive ability of a system to respond to disruptions and continue to operate, albeit not necessarily as it did initially.
\end{abstract}

Keywords: Complex Systems, Inter-disciplinary, Adaptive, Resilient, Interdependent

\section{INFRASTRUCTURE SYSTEMS}

Infrastructure systems have been built traditionally for the long-run as exemplified by the Victorian's visionary infrastructures. Regardless of the funder and their motives (such as social and economic well-being) there is an embedded often explicit assumption of the investments worthwhile nature based on some cost-benefit that will arise contingent upon the use made of the infrastructure. This most often implies that the system will need to be uninterrupted and undisturbed otherwise benefits delivery would be compromised. It is not surprising therefore, that infrastructure systems have been kept separate and isolated as far as possible using controls to ensure benefits delivery. These controls are evidenced by legislation, regulation, functional departments and organizations (e.g. electricity, water), disciplinary (academic) specialization and industrial (and professional) groups. These controls act as negative feedback to ensure a status quo in the infrastructure system creating inertia and leads to sweating of assets and avoidance of adaptation.

Lives in the $21^{\text {st }}$ century are however very far from static and unchanging. Indeed they highlight the very nature of interdependencies in infrastructure systems often driven by the innovation of new technologies and integration of services. The services extracted from infrastructure, are at least for the domestic market, converge at the consumer level. Examples, facilitated by new technologies, include information on the move (ICT and transport convergence), increasing use of electric and hybrid vehicles (energy and transport) and on demand hot water (energy and water). Integrating devices, such as sat navs, electric car batteries, and combi-boilers, join up multiple infrastructure systems. 
However at the infrastructure system and sub-system levels, there is even greater interdependency ${ }^{1},{ }^{2},{ }^{3,},{ }^{4}$ such as electricity production dependent on water and ICT, with transport dependent on energy and ICT, and with water treatment dependent on transport and waste.

These interdependencies create connected networks not only during the operation of the systems, but also in their build and de-commissioning phases.

\section{PATTERNS OF INTERDEPENDENCY}

Two key issues are evident as a result of these interdependencies. First, is that as interdependencies become more closely coupled through the dynamics of use, inertia sets in, there will be an increased probability of greater impact of a disruption, especially in cases of single point of failure. For example, use of rail transport for long-distance commuting can be disrupted by power outages. However business continuity is an organizational matter and is not usually addressed at small scale, e.g. domestic environments, nor between meso and large scale infrastructure systems. Second, is that interdependency may operate without the knowledge of one or other infrastructure provider until a disruption occurs. Novel uses of infrastructure emerge to meet demands, such as the use of railway defences against flood, and digital communications to circumvent traffic issues.

Big data technologies which capture infrastructure use and condition data in real time and detect patterns of use across infrastructure systems, can 1. highlight points of conversion in infrastructure systems which are vulnerabilities, and 2. help transform knowledge about adaptation. They can inform scientific discovery of resilient dynamical structures, and provide evidence for management of risk and steering future change. This information would be cross-cutting, e.g. such as demand forecasting, and has the potential to reduce the effect of disruptions to infrastructure, and to those in the organizations and supply chains providing these services. Diagnostic information can also be tracked, because in complex systems the areas of impact are often far removed from the sources of the problem, for example a blocked water main may create floods in unexpected places.

This approach is especially important because the issues are exacerbated by contextual factors, such as increasing, aging and affluent population and in particular urbanization, globalization and interconnected economies, changes in weather patterns (such as stronger winds, heavier and prolonged rain-fall, larger tides and extremes of temperature), and also the risk and reality of terrorism and security attack. These contextual factors exacerbate the pressure on interdependent infrastructures as more people are affected and conditions make it difficult to achieve a return to normal operation services.

\section{SUSTAINABLE DEVELOPMENT, ADAPTATION AND NORMATIVE FUTURES}

A further significant context is the need for sustainable development and preservation of resources and the environment. Following the United Nations 2005 World Summit ${ }^{5}$, sustainable development was defined as the interdependent and mutually reinforcing pillars of economic development, social development and environmental protection.

Coupled with sustainable development is a fundamental desire to create adaptable infrastructure systems which are adaptable in response to changing demand and contextual circumstances. Adaptive development is the institutional capacity to cope with change ${ }^{6}$. It is about survival and changing parts of systems so that they function better with

1 Heller, M., (2001). Interdependencies in Civil Infrastructure Systems. The Bridge, Vol. 31, No. 4, pp. 9-15.

2 Rinaldi, S. M., Peerenboom, J. P. and Kelly, T. K. (2001). Identifying, Understanding, and Analyzing Critical Infrastructure Interdependencies. IEEE Control Systems Magazine, Vol. 21, No. 6, pp. 11-25.

3 Dunn, M., (2005). The socio-political dimensions of critical information infrastructure protection (CIIP). International Journal of Critical Infrastructures, Vol. 1, No. 2/3, pp. 258-268.

4 O'Rourke, T. D., (2007). Critical Infrastructure, Interdependencies, and Resilience. The Bridge, Vol. 37, No. 1, pp. $22-29$.

5 United Nations (2005), United Nations World Summit Outcome, Sixtieth session - Items 48 and 121 of the provisional agenda (A/60/150), available online at www.who.int/hiv/universalaccess2010/worldsummit.pdf

6 Marten, G. (2001) Human Ecology: Basic Concepts for Sustainable Development, Earthscan, London, UK 
interacting systems, and create capacity to deal with disruptions. Adaptive development requires regular assessment and corrective action ${ }^{6}$. Ashby ${ }^{7}$ suggests that adaptability is enhanced among the system's components if there is a modest degree of interaction among the system's components. In what Ashby terms, a fully joined system, a perturbation in one variable requires adjustment in all other variables of the system, making adaptation improbable ${ }^{8}$. Perrow ${ }^{9}$ makes a similar argument when analysing the possibility of "normal" accidents in complex, tightly coupled systems. Tightly coupled firms can not engage in exploration without foregoing the benefits of exploitation. In addition, we are entering an era of climate change and uncertainty - it is no longer tenable to manage for the mean we need to "manage for the variance", as unpredictability in weather patterns become the norm - potentially hugely significant for future urban planning and design ${ }^{10}$.

It follows that a transformative teleological position ${ }^{11}$ is needed to steer interdependent systems towards normative futures which can be shaped and re-shaped along with the infrastructure systems which enable them. We cannot know the extent to which the future is recognizable today, nor how we will perceive our dependency on infrastructure systems. And everyone's perceptions of sustainability, adaptability and resilient systems is unique, since perceptions are value-laden, change over time, and in response to needs; a pluralistic epistemology must prevail which embraces difference and inter-disciplinarity and importantly acknowledges the limitations of absolute analysis ${ }^{12}$.

\section{RESILIENCE ASSESSMENT}

Resilience is defined as "the capacity for an enterprise to survive, adapt and grow in the face of turbulent change"13. This is a concept that has been prevalent in understanding the way in which natural systems respond to perturbation and change, since the 1970's with a focus on "functions"14 or a narrower emphasis on return to "pre-disturbance" state $^{15}$. This is still subject of much debate, with recent work demonstrating that there is both "helpful" and "unhelpful" resilience - the latter keeping a system in an undesirable state once a threshold or tipping point has been crossed $^{16}$.

Systems are resilient if they are able to continue functioning despite occasional and severe disturbances. Methods to achieve resilience include 1. Redundancy: duplication and diversification which replace parts that go wrong, and (in natural systems) species which have overlapping roles and niches, e.g. multiple forms of power generation serving overlapping parts of a city, and 2. Low dependence on human inputs which is desirable since it reduces interference with resilience. Resilience is desirable but requires extra cost and effort and conflicts with global economic pressures to increase efficiency and related low operating costs essential for survival in modern firms ${ }^{6}$. Resilience is not to be confused with reliability which is defined as the probability of a network remaining functional during a disruption ${ }^{17}$.

7 Ashby, W. R. (1960), Design for a Brain, John Wiley \& Sons, New York.

8 Glassman, R. B. (1973), Persistence and Loose Coupling in Living Systems, Behavioural Science, vol. 18, pp. 83-98.

9 Perrow, C. (1984), Normal Accidents: Living with High-Risk Technologies, Basic Books, New York.

10 Braun, B. P. (2014), A new urban dispositif? Governing life in an age of climate change, Environment and Planning D: Society and Space, vol. 32, pp. $49-64$.

11 Stacey, R.D., Griffin, D., and Shaw, P. (2000), Complexity and Management - Fad or Radical challenge to systems thinking? Routledge, London.

12 Johansen, I. L. and Rausand, M. (2014), Defining complexity for risk assessment of sociotechnical systems: A conceptual framework, Proceedings of the Institution of Mechanical Engineers, Part O: Journal of Risk and Reliability, pp 228: 272. DOI: $10.1177 / 1748006 \times 13517378$

13 Fiksel, J. (2006), Sustainability and Resilience: Toward a Systems Approach, Sustainability: Science Practice and Policy, vol. 2, no. 2, pp. 14-21. See page 16 for citation.

14 Holling, C.S. (1973), Resilience and stability of ecological systems. Annual Review of Ecology and Systematics vol. 4, pp. 1-23.

15 Pimm, S.L. (1984), The complexity and stability of ecosystems, Nature, vol. 307, pp. 321-326.

16 Standish, R.J., Hobbs, R.J., Mayfield, M.M., Bestelmeyer, B.T., Suding, K.N., Loretta L. Battaglia, L.L., Eviner, V., Hawkes, C.V., Temperton, V.M., Cramer ,V.A., Harris , J.A., Funk, J.L., Thomas, P.A.. (2014) Resilience in ecology: Abstraction, distraction, or where the action is? Biological Conservation, vol. 177, pp. $43-51$.

17 Adenso-Diaz, B., Mena, C., García-Carbajal, S. and Liechty, M. (2012), The Impact of Supply Network Characteristics on Reliability, Supply Chain Management, vol. 17, no. 3, pp. 263-276. 


\section{AN AGENT BASED MODEL ASSESSING RESILIENCE OF INTERDEPENDENT INFRASTRUCTURES}

An agent based model is defined using a conversion point ontology ${ }^{18}$. This ontology defines each component of an infrastructure system in terms of the inputs to the component (such as the various resources: grey water, coal, etc.), the controls (such as regulations, cultural norms), the mechanisms (such as the technology used, its capacity, normal operating minima and maxima, its related efficiency, and the skills required for the conversion), and the outputs (including waste, emissions, by-products, and primarily useful outputs, such as heat, power, mobility).
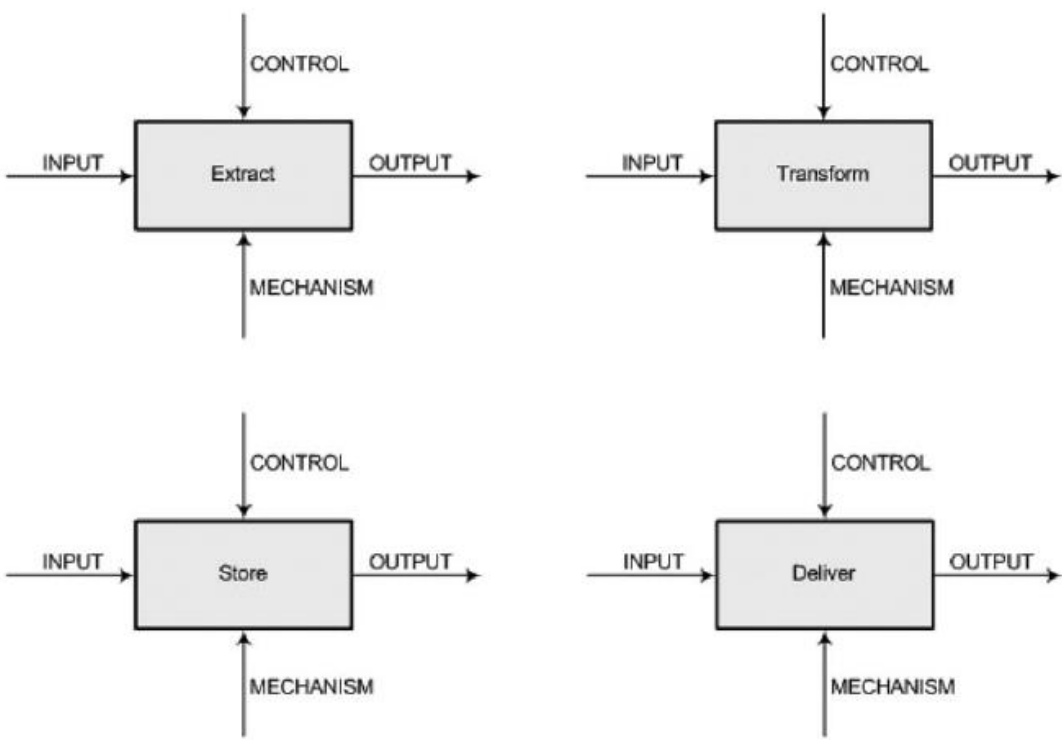

\section{Figure 1: Key activities/services underpinning conversion points ${ }^{14}$}

The ontology allows us to capture interdependencies, whereby the output from one conversion is available to another conversion through a distribution channel which itself is another conversion point (and consumes time, and other resources, and generates losses through the inefficiency of the process). The ontology will work either as a push (supply) system or as a pull (demand) system.

Use big data technologies we collect production and consumption data of all infrastructures within a defined boundary, and using records of real-time feeds we simulate disturbances to the infrastructure systems. This asset data is collected from infrastructure operators, such as Highways Agency, Network Rail, WPD, Anglian Water and EON.

Resilience is indicated by the system's ability to provide essential or desired services (or "functions") through alternative means in the modeled infrastructure system. That is, the adaptive capability of the system is tested. Model outputs are tested using measures of resilience including: temporal and spatial indicators of slowing down, trend analysis and shiftograms ${ }^{19}$, ball and cup model (recovery time, autocorrelation, variance and skewness ${ }^{20}$ ) and Critical Slowing Down and transcritical bifurcation ${ }^{21}$. Network theory is used to identify closed loops, e.g. where component A depends on B, and $\mathrm{B}$ depends on $\mathrm{C}$, and $\mathrm{C}$ depends on $\mathrm{A}$, and to analyse the different network topologies, node centralities, holes, etc. in order to create understanding of the resilience in respect to the networks' topologies.

Tests of full or partial disruptions to one or more points in the infrastructure system are carried out, simulating various types of inter-dependencies are made including geographical and cyber². The use of genetic algorithms to identify the optimal configurations are determined by iterative running of systems difference scenarios of use, e.g. increasing trends in particular directions over time.

18 Varga, L, Grubic, T, Greening, P, Varga, S, Camci, F, Dolan, T (2014) Characterizing conversion points and complex infrastructure systems: Creating a system representation for agent-based modeling, Complexity, Vol. 19, pp. 30-43. DOI: 10.1002/cplx.21521

19 Lindegren, M, Dakos, V., Gröger, J., Gårdmark, A., Kornilovs, G., Otto, S., Möllmann, C. (2012). Early Detection of Ecosystem Regime Shifts: A Multiple Method Evaluation for Management Application, PLOS One, Vol. 7 No. 7.

20 Dakos, V., Kéfi, S. Rietkerk, M., van Nes, E., Scheffer, M. (2011), Slowing Down in Spatially Patterned Ecosystems at the Brink of Collapse. The American Naturalist, Vol. 177, No. 6, pp. E153-E166. http://www.jstor.org/stable/10.1086/659945

21 Chisholma R., Filotas, E., (2009) Critical slowing down as an indicator of transitions in two-species models, Journal of Theoretical Biolog, Vol. 257, pp. 142-149 


\section{EXPECTED RESULTS AND DISCUSSION}

Based on earlier and smaller scale results together with the proposed enhancements developed above, we expect to find the following results:

As the system of systems becomes less diverse and inter-dependencies increase, we expect to see more frequent occurrence and more prolonged time before recovery after disruption, in essence a "critical slowing down" found in natural systems as they approach threshold/transition points ${ }^{22}$, suggesting worsening resilience; vice versa, with greater diversity and less inter-dependence, we expect to find greater resilience but less overall usage of available capacity; that is efficiency might be greater with newer technology, but it may take longer to achieve pay-back on investment.

We expect to find those points (including distribution channels) in the system which have greatest dynamical centrality, that is, frequency of flows (since we are treating all infrastructure systems as having continuous (not batch) flows. These points come under pressure regardless of which points in the system are disrupted and require alternative points or sub-systems to generate adaptive capacity.

The topology type of each system's network is expected to make a difference to resilience with scale-free networks being most resilient. However it is difficult to predict what will emerge as a result of the interdependence of mixed topologies across the three key infrastructure systems (e.g. hierarchical for energy, random for water, and scale free for transport).

Finally we expect that trends such as population increase or urbanization will drive unanticipated and paradoxical outcomes: e.g. slowing down the flow of resources by reducing capacity will increase system throughput. However as flow is severely curtailed we expect alternative technologies to develop in other infrastructure systems to take up demand, e.g. road congestion driving increased telecommunications traffic, local energy provision (meso CHP), and the increased deployment of "hybrid biological/engineered" systems comprising hard and biological components as part of the "Green Infrastructure" of cities ${ }^{23}$. We also anticipate that intelligent autonomous technologies (demanding no or little skills of the user) to increase which will self-organize the system to reduce congestion, improve resilience and avoid waste, including user time.

22 Dakos, V., Carpenter, S.R., Brock, W.A., Ellison, A.M., Guttal, V., et al (2012) Methods for Detecting Early Warnings of Critical Transitions in Time Series Illustrated Using Simulated Ecological Data, PLOS ONE, Vol. 7 No. 7., doi:10.1371/journal.pone.0041010

23 CABE Space (2010) Urban green nation: building the evidence base, UK Commission for Architecture and the Built Environment, London. 